total study, could have diluted any important positive overall effect.

Is not the second explanation the most likely? The results of this trial are disconcertingly similar to those of a Finnish multifactor intervention trial of primary prevention of coronary heart disease, ${ }^{2}$ though the design of the Finnish study was different in that it comprised two cross-sectional surveys of population samples not selected for high risk. An overall mean net reduction of $17 \%$ in men and of $12 \%$ in women occurred five years later with regard to cigarette smoking, blood pressure, and plasma cholesterol concentrations in the intervention community (North Karelia) compared with the control community (Kuopio). But there was no reduction in morbidity from coronary heart disease. Again, risk factors had been reduced in the control community, too.

Or is the first explanation the correct one ? The incubation period of coronary atherosclerosis is far longer than the sevenyear duration of the trial. ${ }^{3}$ We do not yet know the extent, if any, of regression of coronary lesions which occurs in middleaged men even with such successful control of risk factors as was achieved in this trial. It does not follow that intervention to produce minor regression or non-progression of lesions will lead to fewer clinical manifestations of coronary heart disease in those who already have moderate or advanced obstructive arterial disease. Perhaps cigarette smoking, hypertension, and hypercholesterolaemia are not the relevant risk factors to control at this stage; perhaps prevention of the factors which trigger the onset of the clinical syndromes of coronary heart disease would yield more. Thrombosis is an obvious area for more research in relation to these syndromes, but we are only just beginning to identify which indices have predictive power, ${ }^{4}$ let alone how to intervene for primary prevention.

What positive conclusions can be extracted from the Multiple Risk Factor Intervention Trial ? Stopping cigarette smoking in both the intervention and non-intervention groups appears to have reduced coronary heart disease mortality significantly, though confounding factors cannot be excluded. The results of intervention in the subgroup of smokers and men with hypercholesterolaemia were favourable, supporting the findings of the smaller Oslo study, ${ }^{5}$ which showed a reduction in the incidence of coronary heart disease with cessation of smoking and dietary intervention to lower lipid concentrations in nonhypertensive men in high-risk categories. More cannot be said.

What might be expected from the continuing World Health Organisation European trial in industry? This comprises 63732 men aged 40-59 in 44 pairs of factories in Britain, Belgium, Italy, Poland, and Spain; $17 \%$ of these are categorised as high risk for coronary heart disease. An interim report ${ }^{6}$ on the changes in risk factors after two and four years of intervention makes depressing reading. Changes were smaller than expected and not completely consistent or sustained. The authors comment that, despite an estimated fall of $14 \%$ in coronary heart disease risk in the whole group and of $24 \%$ in the high-risk subgroup after four years, no equivalent fall in incidence of coronary heart disease may be shown even in a study of this size. The British experience was reported earlier ${ }^{7}$ : while showing that coronary risk factors can be changed in a working population at modest cost, they were also small and not sustained.

The indecisive results of the Multiple Risk Factor Intervention Trial will not alter the nihilism of the "abominable no-men,"8 though they should temper the fervour of the evangelists-the twin dangers which threaten the formulation of a responsible policy towards prevention of the principal cause of death in developed countries. Much as we might like to think otherwise, it is not yet possible to prevent coronary heart disease in the community-let alone in an individual. And the falling mortality from coronary heart disease in the United States remains largely unexplained and cannot be ascribed wholly to preventive measures. Nevertheless, sensible pragmatic health education should continue to insist on stopping cigarette smoking-and at least this can be reinforced by the results of the Multiple Risk Factor Intervention Trial. Surely, too, a prudent diet with reduction of fat energy and control of obesity and of sloth are sound policies for improving the public health.

M F OLIVER

Duke of Edinburgh Professor of Cardiology,

Cardiovascular Research Unit

University of Edinburgh,

Edinburgh EH8 9FX

${ }^{1}$ Multiple Risk Factor Intervention Trial. Risk factor changes and mortality results. FAMA 1982;248:1465-77.

2 Puska P, Tuomilehto J, Salonen J. Changes in coronary risk factors during comprehensive five-year community programme to control cardiovascular diseases (North Karelia project). Br Med f 1979;ii:1173-8.

${ }^{3}$ Rose G. Incubation period of coronary heart disease. $\mathrm{Br} \mathrm{Med}$ F $1982 ; 284$ : 1600-1.

4 Meade TW. Risk associations in the thrombotic disorders. Clin Haematol $1981 ; 10$, No 2:391-405.

${ }^{5}$ Hjermann I, Byre KV, Holme I, Leren P. Effect of diet and smoking intervention on the incidence of coronary heart disease. Report from the Oslo Study Group of a Randomised Trial in Healthy Men. Lancet 1981 ;ii:1303-10.

6 World Health Organisation European Collaborative Group. Multifactorial trial in the prevention of coronary heart disease. 2. Risk factor changes at two and four years. Eur Heart $\mathcal{F} 1982 ; 3: 184-90$.

${ }^{7}$ Rose G, Heller RF, Pedoe HT, Christie DGS. Heart disease prevention project: a randomised controlled trial in industry. $\mathrm{Br} \mathrm{Med} \mathcal{F} 1980 ; 280$ : 747-51.

8 Anonymous. Abominable no-men. Times Health Supplement 1982 Feb 26: 10 (col 3-5).

\section{Amaurosis fugax}

Commonly the patient with amaurosis fugax is a man aged over $50^{1}$ who complains of one or more episodes of unilateral loss of vision-“like a curtain coming down." Each episode lasts seconds or minutes, occasionally an hour or more. Examination may suggest that cerebral emboli have occurred in the past $^{12}$ and may disclose a carotid bruit on the same side; the classic, but uncommon, finding is the presence of a glistening cholesterol crystal embolus in a retinal arteriole, often at a bifurcation-the Hollenhorst plaque. Then the diagnosis of amaurosis fugax is plain. Its management is not.

If a plaque is not seen other diagnoses must be considered. When the build-up of symptoms is slower, migraine accompagnée may be considered, even without current or past headache. ${ }^{3}$ Monocular visual loss may also complicate cranial arteritis, Raynaud's disease, papilloedema, and retrobulbar neuritis; it may be associated with arteriolar damage from eclampsia, uraemia, paroxysmal hypertension, and porphyria. ${ }^{4}$ Blood disorders such as polycythaemia, ${ }^{5}$ thrombocytosis, ${ }^{6} 7$ anaemia, and thrombocytopaenic purpura may be considered, as may cardiac lesions-prolapse of the mitral valve, ${ }^{89}$ atrial myxoma, ${ }^{10}$ and bicuspid aortic valve ${ }^{11}$-particularly with episodes lasting longer than an hour. ${ }^{12}$ In practice, however, artery-to-artery embolism accounts for over $90 \%$ of all cases. ${ }^{113}$

A waiting policy is perilous ${ }^{14}$ : about a third of patients with amaurosis fugax may go on to have a stroke within five years. 
half of these within one year and especially within the first two months ${ }^{15}$ though a better prognosis has been reported in some series. ${ }^{16}$ The risk to sight is not great, a permanent retinal infarction being uncommon. The mortality is substantial, however: in one series $41 \%$ of untreated patients died from strokes or myocardial infarcts within five years, $13 \%$ continued with some form of transient ischaemic attack, and the remainder were asymptomatic or had survived myocardial infarctions. ${ }^{17}$ In other studies of treated patients, nearly half went on to have transient ischaemic attacks or stroke, and half also developed peripheral vascular or ischaemic heart disease within five years. ${ }^{131819}$ The frequency and duration of episodes of amaurosis fugax are unrelated to the risk of later cerebral vascular accident. ${ }^{13} 20$

Given that investigations are justified by these figures, what should be done, and to whom? In patients under the age of 55, $90 \%$ of the men have extracranial arterial disease but $70 \%$ of the women have coagulation disorders, ${ }^{21}$ and women patients are generally younger. ${ }^{1319}{ }^{21}$ Risk factors such as lipid disorders, hypertension, diabetes, and smoking are common ${ }^{1322}$ and treatable, ${ }^{23}$ and must be defined. Since surgery may be indicated, the site and nature of the responsible lesion (usually in the common or internal carotid, seldom in the external carotid or ophthalmic arteries) must be defined by, for example, transfemoral angiography, and if necessary by direct puncture of the carotid artery in the neck. Such abnormalities are most likely in patients aged over 50, especially if they are hypertensive, if they have evidence of a past transient ischaemic attack or stroke, or have intermittent claudication or an ipsilateral carotid bruit; a combination of any of these factors appreciably increases the likelihood of finding an abnormality on angiography. ${ }^{13}$ Transient ischaemic attacks lasting less than one hour are also more likely to be associated with an abnormal angiogram, ${ }^{124}$ though operable lesions have been found in all subgroups of patients.

All patients aged over 50 who manifest the above four factors will probably be found to have operable lesions shown by angiography, as will $75 \%$ of those with only two of them. Under that age, such findings occur in only a fifth of patients. ${ }^{20}$ Unfortunately, even in experienced hands angiography carries a high morbidity: neurological or cardiac complications have been recorded in up to $12 \%$ of patients ${ }^{125}$ and the mortality may be $0.6 \%{ }^{17}$ even in a highly competent centre. Probably, therefore, angiography should be performed in all patients with amaurosis fugax over the age of $50^{13}$ while other sources of emboli or haematological disorders should be sought first in younger patients.

The fourth and greatest problem concerns treatment, the choices being surgery, anticoagulation, or antiplatelet treatment. Since carotid stenosis may be seen-and often heardit has been the most studied, though the ulcerated plaque may be equally important as a source of emboli. ${ }^{1926}$ No consensus can be found on the value of endarterectomy. Toole and his colleagues $^{17}$ found no differences related to cerebral infarction or transient ischaemic attacks among patients treated by medical or surgical means or not treated (results generally confirming those of the American joint study ${ }^{27}$ ). In contrast, the Mayo Clinic group believes that carotid endarterectomy can reduce symptoms of transient ischaemic attacks and may lower the risk of stroke in selected patients. ${ }^{15}$ These forecasts require qualification: the surgeon must be experienced; the presence of cardiac disease, multiple or inaccessible arterial lesions or carotid occlusions on either side, or of a fixed neurological deficit all greatly increase the operative risk,,$^{131528}$ as do hypertension, ischaemic heart disease, advancing age, obesity, and pulmonary disease. When amaurosis fugax occurs with carotid occlusion anastomosis of the middle cerebral and superficial temporal arteries does not appear to reduce the chance of further strokes. ${ }^{29}$ An acceptable risk for endarterectomy may be taken as a $2 \%$ mortality and morbidity. ${ }^{15}$ The much higher figures variously reported ${ }^{30}$ may reflect a previous tendency of physicians to ignore the risk factors now defined. The most suitable patients are those with a transient ischaemic attack (including amaurosis fugax) and unilateral carotid stenosis of greater than $50 \%{ }^{1531}$ but with no residual neurological findings. In the well-defined series reported by Parkin et al ${ }^{13} 14$ of 20 patients with amaurosis fugax had complete or partial relief of symptoms after endarterectomy over almost a five-year period. Several of these patients, however, were also given antiplatelet agents.

Five prospective double-blind studies ${ }^{27} 31-34$ have shown differences between placebo and aspirin (but not sulphinpyrazone) in the prevention of transient ischaemic attacks or stroke, particularly among older normotensive men; all the differences have favoured aspirin. ${ }^{35}$ The similarity between the results of the Canadian and the Italian studies is striking. Unfortunately, amaurosis fugax and other transient ischaemic attacks are markers of diffuse vascular disease and no statistically significant reduction of mortality from, for example, myocardial infarction has been shown. ${ }^{36}$

Treatment of risk factors, especially hypertension, must not be omitted. Reductions of the usual rate of recurrent cardiovascular accidents $(20 \%$ to $40 \%)$ and mortality rate from all causes at five years $(35 \%$ to $65 \%$ ), to $16 \%$ and $17 \%$ respectively $^{22}$ have been achieved by such treatment. Anticoagulation has been employed with only occasional success in preventing recurrent stroke or in increasing survival, 17333738 though the frequency of transient ischaemic attacks may be temporarily reduced. The danger of intracerebral bleeding is up to eight times greater than expected in patients over 55, even if the prothrombin index is not unduly prolonged. ${ }^{38-40}$ Concluding an exhaustive review of the literature, Brust ${ }^{41}$ commented: "That anticoagulants may be of value in transient ischaemic attacks thus remains an unproved hypothesis, with all studies to date lacking either randomised controls or statistical significance"-thus censuring a profession which claims a scientific basis for its treatments.

More recently, the Mayo group ${ }^{15}$ has brought forward "suggestive evidence" that anticoagulant treatment decreases the risk of stroke in patients with carotid transient ischaemic attacks, primarily in the first few months after their onset, but in an even more recent report ${ }^{40}$ anticoagulation increased morbidity without providing substantial benefits.

What management plan for patients with amaurosis fugax emerges from all these data ? The diagnosis is to be established by the usual clinical methods, and the presence of those clinical factors most likely to be associated with an operable carotid lesion should be noted. At the same time, alternative lesions possibly producing emboli must be excluded. Risk factors, especially hypertension, must be sought by clinical and laboratory studies and energetically treated. When no haematological disorder or alternative source of emboli can be found patients aged over 50 should be offered carotid angiography, preferably bilaterally, by the femoral route, by an experienced angiographer, and provided that medical and neurological contraindications have been excluded. Patients below 50 probably need angiography only if they have evidence of hypertension, carotid bruit, claudication, or evidence of other transient ischaemic attacks or residual features from old infarcts. Those patients with an obvious focal lesion of the 
appropriate carotid artery may be referred to an experienced surgeon for endarterectomy and afterwards they and probably all other men patients may best be given aspirin in low dosage, ${ }^{42}$ probably permanently. In women, such treatment is probably safe but of uncertain value, as is the use of sulphinpyrazone. The value of anticoagulants is not proved, but if symptoms persist despite the above treatments a three-month course may be warranted. Follow-up should be life long.

\section{William Pryse-Phillips}

Professor of Medicine (Neurology),

Memorial University of Newfoundland,

St John's,

Newfoundland A1B 3V6

${ }^{1}$ Heyman A, Burch JG, Rosati R, Haynes C, Utley C. Use of a computerized information system. In: The management of patients with transient cerebral ischemia. Neurology (NY) 1979;29:214-21.

${ }^{2}$ Harrison MJG, Marshall J. Evidence of silent cerebral embolism in patients with amaurosis fugax. $\mathcal{F}$ Neurol Neurosurg Psychiatry 1977;40: 651-4.

${ }^{3}$ Fisher CM. Late-life migraine accompaniments as a cause of unexplained transient ischemic attacks. Canad $\mathcal{F}$ Neurol Sci 1980;7:9-17.

4 Anonymous. Episodic blindness. Br Med f 1972;ii:122-3.

${ }^{5}$ Millikan $\mathrm{CH}$, Siekert RG, Whisnant JP. Intermittent carotid and vertebral-basilar insufficiency associated with polycythemia. Neurology $(N Y)$ 1960;10:188-96.

${ }^{6}$ Mundall J, Quintero P, Von Kaulla KN, et al. Transient monocular blindness and increased platelet aggregability treated with aspirin. A case report. Neurology (NY) 1972;22:280-5.

7 Preston FE, Martin JF, Stewart RM, Davies-Jones GAB. Thrombocytosis, circulating platelet aggregates, and neurological dysfunction. $\mathrm{Br} \mathrm{Med} \mathcal{F}$ 1979 ;ii :1561-3.

${ }^{8}$ Caltrider ND, Irvine AR, Kline HJ, Rosenblatt A. Retinal emboli in patients with mitral valve prolapse. Am $\mathcal{F}$ Ophthalmol 1980;90:534-9.

${ }^{9}$ Shapiro SK, Warshawsky R, Shapiro I, et al. Neurological and ophthalmological complications of mitral valve prolapse. Minn Med 1981 ;64:197-9.

10 Sandok BA, Von Estorff I, Giuliani ER. CNS embolism due to atrial myxoma. Clinical features and diagnosis. Arch Neurol 1980;37:485-8.

11 Pleet AB, Massey EW, Venrow ME. TIA, stroke, and the bicuspid aortic valve. Neurology (NY) $1981 ; 31: 1540-2$

12 Harrison MJG, Marshall J, Thomas DJ. Relevance of duration of transient ischaemic attacks in carotid territory. $B r$ Med $\mathcal{F} 1978 ; 1: 1578-9$.

13 Parkin PJ, Kendall BE, Marshall J, McDonald WI. Amaurosis fugax : some aspects of management. 7 Neurol Neurosurg Psychiatry 1982;45:1-6.

14 Hooshmand H, Vines FS, Lee HM, et al. Amaurosis fugax: diagnostic and therapeutic aspects. Stroke $1974 ; 5: 643-7$.

${ }^{15}$ Sandok BA, Furlan AJ, Whisnant JP, Sundt TM Jr. Guidelines for the management of transient ischemic attacks. Mayo Clin Proc 1978;53 665-74.

${ }^{16}$ Loeb C, Priano A, Albano C. Clinical features and long-term follow-up of patients with reversible ischemic attacks (RIA). Acta Neurol Scand $1978 ; 57: 471-80$

17 Toole JF, Yuson CP, Janeway R, et al. Transient ischemic attacks: prospective study of 225 patients. Neurology (NY) 1978;28:746-53.
18 Simonsen N, Christiansen HD, Heltberg A, Marquardsen J, Pedersen HE, Sørensen PS. Long-term prognosis after transient ischemic attacks. Act Neurol Scand $1981 ; 63: 156-68$.

19 Marshall J, Meadows S. The natural history of amaurosis fugax. Brain 1968;91:419-34.

${ }^{20}$ Wilson LA, Russell RWR. Amaurosis fugax and carotid artery disease: indications for angiography. $\mathrm{Br} M e d \mathcal{F} 1977$;ii:435-7.

${ }^{21}$ Mettinger KL, Söderström CF. Pathogenetic profile of TIA before 55. A three-year investigation. $f$ Neurol $S_{c i} 1978 ; 36: 341-8$.

${ }^{22}$ Mungas JE, Baker WH. Amaurosis fugax. Stroke 1977;8:232-5.

${ }^{23}$ Leonberg SC, Elliott FA. Prevention of recurrent stroke. Stroke $1981 ; 12$ 731-5.

${ }^{21}$ Humphrey PRD, Marshall J. Transient ischemic attacks and strokes with recovery prognosis and investigation. Stroke $1981 ; 12: 765-9$.

${ }^{25}$ Eisenberg RL, Mani RL. Clinical and arteriographic comparison of amaurosis fugax with hemispheric transient ischemic attacks. Stroke 1978;9:254-5.

26 Bartynski WS, Darbouze P, Nemir P Jr. Significance of ulcerated plaque in transient cerebral ischemia. Am f Surg 1981 ;242:353-7.

27 Fields WS, Lemak NA, Frankowski RF, Hardy RJ. Controlled trial of aspirin on cerebral ischemia. Part II : surgical group. Stroke 1978;9: 309-19.

${ }^{28}$ Byer JA, Easton JD. Transient cerebral ischemia: review of surgical results. Prog Cardiovasc Dis 1980;22:389-96.

29 Lee MC, Park SH, Ausman JI, Loewenson RB. Lons term clinical outcome in patients with amaurosis fugax and ipsilateral internal carotid artery occlusion with or without MCA-STA anastomosis. Stroke 1981 12:126. (Abstract.)

30 Easton JD, Sherman DG. Stroke and mortality rate in carotid endarterectomy: 228 consecutive operations. Stroke 1977;8:565-8.

${ }^{31}$ Fields WS, Lemak NA, Frankowski RF, et al. Controlled trial of aspirin in cerebral ischemia. Stroke 1977;8:301-14.

32 Candelise L, Landi G, Perrone P, Bracchi M, Brambilla G. A randomized trial of aspirin and sulfinpyrazone in patients with TIA. Stroke $1982 ; 13$ $175-8$

33 The Canadian Cooperative Study Group. A randomised trial of aspirin and sulfinpyrazone in threatened stroke. $N$ Engl f Med 1978;299:53-9.

34 Reuthan R, Domdorf W. Aspirin in patients with cerebral ischemia and normal angiograms or non-surgical lesions. The results of a doubleblind trial. In: Breddin N, Domdorf W, Loew D, et al, eds. Acetylsalicylic acid in cerebral ischemia and coronary heart disease. New York F K Schattaner, 1978:97-196.

${ }^{35}$ Easton JD, Byer JA. Transient cerebral ischemia: medical management Prog Cardiovasc Dis 1980;22:371-7.

36 Hirsch J. Selection and results of antiplatelet therapy in the prevention of stroke and myocardial infarction. Arch Intern Med 1981;141:311-5.

37 Terént A, Andersson B. The outcome of patients with transient ischemic attacks and stroke treated with anticoagulants. Acta Med Scand 1980 208:359-65.

38 Whisnant JP, Cartlidge NE, Elveback LR. Carotid and vertebral-basila transient ischemic attacks: effect of anticoagulants, hypertension, and cardiac disorders on survival and stroke occurrence-a population study. Ann Neurol 1978;3:107-15.

${ }^{39}$ Conneally PM, Kyken ML, Futty DI, et al. Cooperative study of hospita frequency and character of transient ischemic attacks. VIII. Risk factors. F $A M A$ 1978;240:742-6.

40 Muuronen A, Kaste $M$. Outcome of 314 patients with transient ischemic attacks. Stroke $1982 ; 13: 24-31$.

${ }^{41}$ Brust JC. Transient ischemic attacks: natural history and anticoagulation Neurology (NY) 1977;27:701-7.

$42 \mathrm{Jaffe}$ EA, Weksler BB. Recovery of endothelial cell prostacyclin production after inhibition by low doses of aspirin. $\mathcal{f}$ Clin Inv'est $1979 ; 63: 532-5$. 